\title{
Tuneable Operation of Core and Cladding Pumped Holmium Fibre Lasers
}

\author{
N. Simakov ${ }^{1,2}$, A. Hemming ${ }^{1}$, W. A. Clarkson ${ }^{2}$, A. Carter $^{3}$ and J. Haub \\ 1. Electronic Warfare and Radar Division, Defence Science and Technology Organisation - Edinburgh, South Australia 5111, Australia \\ 2. Optoelectronics Research Centre, University of Southampton - Southampton, SO17 1BJ, UK. \\ 3. Nufern Inc - 7 Airport Park Road, East Granby, CT 06026-9523, USA
}

Holmium fibre lasers are required for remote sensing, LIDAR and some medical applications. In comparison to thulium fibre lasers, the holmium emission provides efficient access to the $2070 \mathrm{~nm}-2150 \mathrm{~nm}$ wavelength range [1, 2]. We present the first report of the tuneable range of a resonantly, cladding pumped holmium fibre laser. This is compared to the tuning range of a core pumped holmium doped fibre.

Both lasers were pumped by a single mode thulium fibre laser at $1950 \mathrm{~nm}$. The core pumped holmium doped fibre (HDF) had a doping concentration of $0.25 \mathrm{wt} . \%$, core diameter of $10 \mu \mathrm{m}, 0.15$ numerical aperture (NA) and length of $2 \mathrm{~m}$ [3]. The cladding pumped fibre had a doping concentration of $0.5 \mathrm{wt} . \%$, core diameter of $18 \mu \mathrm{m}, 0.08 \mathrm{NA}$ and length of $3.5 \mathrm{~m}$ [4]. The pump light was guided by a layer of fluorine doped silica with a NA of 0.2 around an octagonal shaped cladding (114 $\mu \mathrm{m}$ flat-to-flat). Both fibres had robustly single mode cores with a cut off wavelength of $\sim 1950 \mathrm{~nm}$. As shown in Figure 1a, the laser cavity was formed between a diffraction grating and a Fresnel reflection from the opposite end of the fibre.

The tuning ranges of both fibres are shown on Figure $1 \mathrm{~b}$. The tuning range of the core-pumped system was limited by feedback occurring between the thulium pump and holmium emission at wavelengths below $2040 \mathrm{~nm}$. At the longer wavelength end of the emission spectrum the operating wavelength was limited by parasitic lasing at $\sim 2080 \mathrm{~nm}$ between the two perpendicularly cleaved fibre end facets and the diminishing small signal gain at wavelengths $>2100 \mathrm{~nm}$. The core pumped system reached a maximum power of $3.2 \mathrm{~W}$ at $2070 \mathrm{~nm}$. The tuning range of the cladding pumped system was limited by parasitic lasing at $\sim 2100 \mathrm{~nm}$ between the two perpendicularly cleaved end facets of the fibre; the cladding pumped system produced a maximum power of $14.4 \mathrm{~W}$ at $2105 \mathrm{~nm}$. Both the core and cladding pumped lasers were limited in output power by the amount of pump delivered to the active fibre.
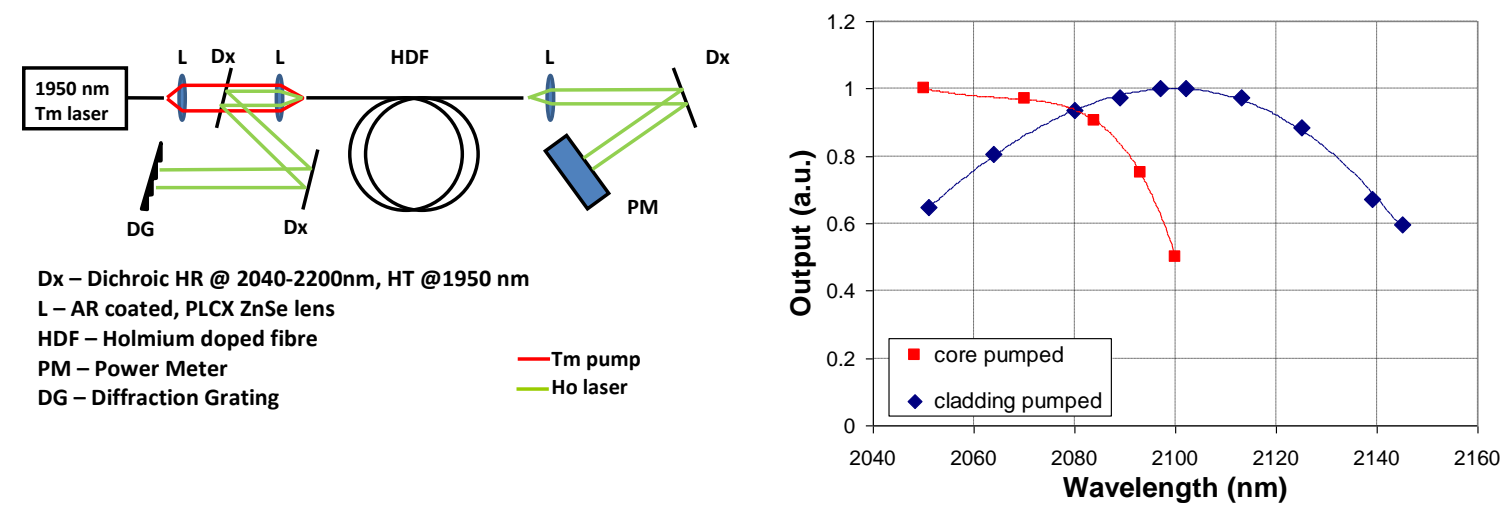

Fig. 1 a) Schematic of experiment b) Tuning performance of the core pumped and cladding pumped holmium fibre lasers (points are experimental data, lines are for assisting viewing only)

The tuning ranges are compared to modeling which considers the absorption and emission cross sections of holmium, IR absorption in silica and $\mathrm{OH}^{-}$impurity absorption. Further optimization and power scaling of cladding pumped holmium fibre lasers is discussed.

\section{References}

[1] D. Shen, J. Sahu, and W. Clarkson, "High-power widely tunable Tm:fibre lasers pumped by an Er,Yb co-doped fibre laser at 1.6 ?m," Opt. Express 14, 6084-6090 (2006).

[2] A. S. Kurkov, E. M. Sholokhov, O. I. Medvedkov, V. V. Dvoyrin, Yu. N. Pyrkov, V. B. Tsvetkov, A. V. Marakulin, and L. A. Minashina, "Holmium fiber laser based on the heavily doped active fiber," Laser Phys. Lett. 6 (9), 661-664 (2009).

[3] S. Hollitt, N. Simakov, A. Hemming, J. Haub, and A. Carter, "A linearly polarised, pulsed Ho-doped fiber laser," Opt. Express 20, $16285-16290$ (2012).

[4] A. Hemming, S. Bennetts, N. Simakov, J. Haub, and A. Carter, "Development of resonantly cladding-pumped holmium-doped fibre lasers," Proc. SPIE8237, 82371J, (2012) 